TITLE:

\title{
Regular ingestion of cinnamomi cortex pulveratus offers gastroprotective activity in mice.
}

$\operatorname{AUTHOR}(S)$ :

Tankam, Joan Manjuh; Sawada, Yuki; Ito, Michiho

\section{CITATION:}

Tankam, Joan Manjuh ...[et al]. Regular ingestion of cinnamomi cortex pulveratus offers gastroprotective activity in mice.. Journal of Natural Medicines 2012, 67(2): 289-295

\section{ISSUE DATE:}

2012-07-04

URL:

http://hdl.handle.net/2433/198451

\section{RIGHT:}

The final publication is available at Springer via http://dx.doi.org/10.1007/s11418-0120680-9.; This is not the published version. Please cite only the published version.; この論 文は出版社版でありません。引用の際には出版社版をご確認ご利用ください。 
Journal of Natural Medicines (Original Paper)

Regular ingestion of cinnamomi cortex pulveratus offers gastroprotective activity in mice

Joan Manjuh Tankam, Yuki Sawada, Michiho Ito*

Department of Pharmacognosy, Graduate School of Pharmaceutical Science, Kyoto University, 46-29 Yoshida-Shimoadachi-cho, Sakyo-ku, Kyoto 606-8501, Japan

*Corresponding Author: E-mail: michihoi@pharm.kyoto-u.ac.jp 


\begin{abstract}
The present study investigated the gastroprotective effects of a cinnamon diet using different gastric ulcer mouse models. Dose dependency and the effective dose period of administration of a cinnamon powder diet were established using the water immersion stress gastric ulcer model. A cinnamon powder diet significantly protected mice against ulceration by stress, ethanol, $\mathrm{HCl}$ and oral administration of aspirin, but not against ulceration by oral administration of indomethacin or subcutaneous administration of indomethacin or aspirin. Such a diet conferred protection against gastric ulcers at an effective concentration of $100 \mathrm{mg}$ cinnamon powder per gram of food after administration for four weeks and the active compound of cinnamon powder for gastroprotective activity was identified as cinnamaldehyde. These findings indicate that regular ingestion of cinnamon powder offers gastroprotection through a cytoprotective mechanism but the efficacy against NSAIDs- induced gastric ulcers may be limited.
\end{abstract}

Keywords: Cinnamomum cassia powder; Gastric ulcer; Gastroprotection; Regular ingestion; Synergism

\title{
Abbreviations:
}

EACC: Ethylacetate extract of Cinnamomum cassia 


\section{Introduction}

Gastric ulcer disease is prevalent in many parts of the world. Although chronic disease is primarily caused by Helicobacter pylori infection, gastric ulcers are aggravated by the use of nonsteroidal anti-inflammatory drugs (NSAIDs), excessive alcohol intake and stress [1, 2]. Several naturally occurring agents, including spices, are known to augment the mucosal defense so that the gastric mucosa can resist strong irritants such as concentrated ethanol, acid, and NSAIDs [3].

Cinnamomum cassia Blume (Lauraceae), known as cinnamon in its stem bark form, is listed in the Japanese Pharmacopoeia. It is a common spice that is often included in Kampo formulae for stomach problems such as gastric ulcers [4], and aqueous extracts of C. cassia have been shown to have anti-ulcerogenic potential $[5,6]$. Cinnamon is commonly used in powder form, although scientific evidence of the gastroprotective benefits of whole cinnamon powder is lacking, and the effects of long term ingestion have not been established. This study therefore aimed to investigate the gastroprotective benefits of regular ingestion of $C$. cassia powder and attempted to clarify the active compounds and mechanisms of action involved in its gastroprotective activity.

\section{Materials and Methods}

\section{Animal care}

Three-week-old male ddY mice (12 g) purchased from Japan SLC, Shizuoka, Japan were used for this study. They were kept under an ambient temperature of $25 \pm 2{ }^{\circ} \mathrm{C}$ and a 
relative humidity of 50-60\% with a light-dark cycle of $12 \mathrm{~h}$. Animals were fed laboratorymade pellet chow and water ad libitum. Animal experiments were designed following recommendations by the Animal Research Committee of Kyoto University, Kyoto, Japan (Approval number 2010-22). Experimental procedures involving animals and their care were conducted in conformity with institutional guidelines that complied with the Fundamental Guidelines for Proper Conduct of Animal Experiment and Related Activities in Academic Research Institutions under the jurisdiction of the Ministry of Education, Culture, Sports, Science and Technology, Japan (2006).

\section{Drugs and reagents}

Cinnamomi cortex used in this study was purchased from Vinh Phuc Co. Ltd (Tam Ky, Vietnam) and was pulverized by Mitsuboshi Co. (Nara, Japan). Indomethacin and sucralfate were purchased from Nacalai Tesque (Kyoto, Japan). Sucralfate was dissolved in 1\% carboxymethylcellulose (CMC) and administered orally (500 mg/kg) as a positive control 45 min before ulcerogenesis. All other drugs and reagents used in this study were of the highest grade commercially available.

\section{Administration of cinnamon powder}

Cinnamon powder was administered to animals via their diet for four weeks prior to ulcerogenesis. The cinnamon diet was prepared as follows: C. cassia powder was mixed with powdered animal feed at a concentration of $100 \mathrm{mg} / \mathrm{g}$ of feed. Distilled water was added to make pellets approximately $1.5 \mathrm{~cm}$ in diameter. The pellets were frozen at $-20{ }^{\circ} \mathrm{C}$ for $24 \mathrm{~h}$ and freeze-dried for $24 \mathrm{~h}$. Control groups were administered similarly prepared pellets without cinnamon. 


\section{Determination of dose and dose period of cinnamon powder}

To determine the most effective dose of cinnamon powder, four groups of mice ( $n=10$ /group) were administered cinnamon diets containing varying concentrations of cinnamon powder for four weeks. The diet of group 1 contained $2 \mathrm{mg}$ of cinnamon powder per g of feed, group 2 contained $10 \mathrm{mg} / \mathrm{g}$, group 3 contained $100 \mathrm{mg} / \mathrm{g}$ and the control group was fed pellet chow without cinnamon powder. Ulcers were evoked in all groups by water immersion stress at 7 weeks and mucosal injury measurements were made as described below. To determine the optimal dose period, mice were divided into three groups. Mice in group 1 were administered the cinnamon diet one week prior to ulcerogenesis, mice in group 2 were placed on the cinnamon diet for two weeks preceding gastric ulcer induction while those in group 3 were placed on the cinnamon diet for four weeks preceding gastric ulcer induction. All animals were fed simple pellet chow when they were not on the cinnamon diet. Control groups were fed pellet chow without cinnamon powder for four weeks.

\section{Gastric ulcer induction}

Mice were divided into four groups of 10 , and each group was subjected to a different method of ulcerogenesis. All animals were fasted for $24 \mathrm{~h}$ on water before ulceration and were sacrificed by i.p. injection of sodium pentobarbital anaesthesia (500 $\mathrm{mg} / \mathrm{kg}$ of body weight). The methods of ulcerogenesis were as follows: (1) Water immersion stress-induced ulcerogenesis: Mice were restrained in stress cages and immersed up to their xiphoid in a water bath maintained at $23^{\circ} \mathrm{C}$ for $8 \mathrm{~h}$ prior to sacrifice according to the method of Kuwayama and Eastwood (1985) [7]. (2) Absolute ethanol-induced ulcerogenesis: Animals 
were orally administered 99.5\% absolute ethanol at a dose of $5 \mathrm{ml} / \mathrm{kg}$ body weight $1 \mathrm{~h}$ before sacrifice. (3) HCl-induced ulcerogenesis: $0.6 \mathrm{M} \mathrm{HCl}$ was administered orally to animals at a dose of $5 \mathrm{ml} / \mathrm{kg}$ body weight $1 \mathrm{~h}$ before sacrifice. (4) NSAID-induced ulcerogenesis: Each group received one of the following treatments 4 h before sacrifice; Group 1 were orally administered indomethacin (35 mg/kg body weight), group 2 were orally administered aspirin (200 mg/kg body weight), group 3 received a subcutaneous injection of indomethacin ( $35 \mathrm{mg} / \mathrm{kg}$ body weight), and group 4 received a subcutaneous injection of aspirin (200 mg/kg body weight). Indomethacin was dissolved in $5 \% \mathrm{NaHCO}_{3}$, while aspirin was dissolved in 5\% arabia gum before administration. All administered doses were based on previously reported data $[8,9,10]$.

\section{Gastric mucosal lesion measurement}

After sacrifice, mouse stomachs were removed and incised along the greater curvature. Gastric contents were emptied, and the stomachs were rinsed with saline and fixed in 1\% formalin. Gastric mucosal lesions were observed under a microscope at 10× magnification, and the lengths of all ulcerogenic lesions per stomach were measured. The sum of the lengths of all ulcerogenic lesions per stomach was taken as the ulcer index, which represented the severity of gastric injury.

\section{Measurement of gastric mucosa thickness}

Mice were divided into two groups of 20. One group was placed on the cinnamon diet for four weeks while the control group was fed ordinary pellet chow for four weeks. After sacrifice, the stomachs were removed, fixed in $1 \%$ formalin then in $10 \%$ formalin. Fixed stomachs were embedded in paraffin, and cut at the pyloric antrum into 5- $\mu$ m thick sections. 
The stomachs of control group mice were cut at the same location as those of the cinnamon treated group. The cut sections were immediately dipped in distilled water and mounted on slides. These were deparaffinized by soaking in xylene twice for 10 min each, rehydrated through graded ethanol solutions (100\% and 95\%) twice for 3 min each, then rinsed in distilled water. Rehydrated slides were stained using the Periodic Acid-Schiff staining method. Histological examination was performed using a light microscope equipped with an ocular micrometer at $400 \times$ magnification and the thickness of the gastric mucosa was measured.

\section{Extraction of cinnamon powder and isolation of active components}

Fifty grams of cinnamon powder was extracted using a Sohxlet apparatus with ethyl acetate to afford approximately $5 \mathrm{~g}$ of extract and $36 \mathrm{~g}$ of debris. The ethyl acetate extract of $C$. cassia (EACC) was evaporated under reduced pressure using a rotary evaporator. The headspace of the extract was analyzed for complete solvent eradication by solid phase micro extraction with gas chromatography (SPME-GC). The analysis was performed on a G7000-M9000/3DQMS system (Hitachi, Tokyo, Japan) under the following operating conditions: column, fused silica capillary column TC-WAX (Hewlett Packard, Palo Alto, CA), $60 \mathrm{~m} \times 0.25 \mathrm{~mm}, 0.25 \mu \mathrm{m}$ film thickness; column temperature, $40-120{ }^{\circ} \mathrm{C}$ increasing at a rate of $16{ }^{\circ} \mathrm{C} / \mathrm{min}, 5 \mathrm{~min}$ at $120{ }^{\circ} \mathrm{C}, 120-130{ }^{\circ} \mathrm{C}$ increasing at $1{ }^{\circ} \mathrm{C} / \mathrm{min}, 15 \mathrm{~min}$ at $130{ }^{\circ} \mathrm{C}, 130-200{ }^{\circ} \mathrm{C}$ increasing at $20^{\circ} \mathrm{C} / \mathrm{min}, 20 \mathrm{~min}$ at $200^{\circ} \mathrm{C}$; carrier gas, He, $147.1 \mathrm{kPa}$; ionization energy, $15 \mathrm{eV}$. To investigate the active components, EACC was fractionated using silica gel open column chromatography (Wakogel C-200, Wako, Osaka, Japan) and eluted with chloroform:AcOEt (2:1) to afford three fractions (Fr. 1-3). 
The biological activity of EACC and that of the fractions were investigated by administering them to mice using the same technique for cinnamon powder described earlier. EACC and fraction doses were calculated according to their proportional yields from cinnamon powder to allow for assessment of the effect of each component on the activity of whole cinnamon powder. Prevention of gastric ulcer by EACC and its fractions was examined using the ethanol-induced ulcer model described earlier because it afforded more visual and distinct ulcerogenesic lesions in control groups than the other ulcerogens. Moreover, the percentage protection against gastric ulcers that cinnamon powder afforded when investigated by using the ethanol model was higher than that of the other ulcerogenic agents.

EACC fractions were further purified by gel permeation chromatography (GPC) (LC-918 recycling high performance liquid chromatography (HPLC) system, JAIGEL-1H and -2H columns, $20 \mathrm{~mm} \times 600 \mathrm{~mm}$ (Japan Analytical Industry, Tokyo, Japan), eluted with $\mathrm{CHCl}_{3}$ (flow rate $3.0 \mathrm{ml} / \mathrm{min}$ ), and preparative thin layer chromatography (PTLC) followed by HPLC and gas chromatography-mass spectrometry (GC/MS) analysis was performed. GC/MS analysis was performed on an Automass (JEOL, Tokyo, Japan) under the following operating conditions: column, fused silica capillary column TC-WAX (Hewlett Packard), $60 \mathrm{~m} \times 0.25 \mathrm{~mm}$, film thickness, $0.25 \mu \mathrm{m}$; column temperature, $40-130{ }^{\circ} \mathrm{C}$ increasing at a rate of $2{ }^{\circ} \mathrm{C} / \mathrm{min}, 25 \mathrm{~min}$ at $130{ }^{\circ} \mathrm{C}, 130-140{ }^{\circ} \mathrm{C}$ increasing at $2{ }^{\circ} \mathrm{C} / \mathrm{min}, 15 \mathrm{~min}$ at $140{ }^{\circ} \mathrm{C}$, $140-200{ }^{\circ} \mathrm{C}$ increasing at $15^{\circ} \mathrm{C} / \mathrm{min}, 30 \mathrm{~min}$ at $200{ }^{\circ} \mathrm{C}$; injector, $180{ }^{\circ} \mathrm{C}$, carrier gas, He, $45 \mathrm{~cm} / \mathrm{min}$; column head pressure, $100 \mathrm{kPa}$; injection volume, $1 \mu \mathrm{l}$; ionization energy, 70 $\mathrm{eV}$. Compounds were identified by comparing their retention times, mass and ion spectra 
from an MS data library (NIST 02), and authentic standards. Purified compounds were analyzed by nuclear magnetic resonance (NMR) and Fab-MS to elucidate structures.

\section{Administration of cinnamaldehyde (CA)}

CA was administered to mice using the same method of administration for cinnamon powder described earlier to confirm its gastroprotective activity. Mice were divided into three groups of 10 . Group 1 was administered a diet consisting of CA at a concentration of $0.98 \mathrm{mg} \mathrm{per} / \mathrm{g}$ of feed for four weeks. The diet of group 2 contained $9.8 \mathrm{mg}$ CA /g of feed and control group 3 was administered ordinary mouse feed for four weeks. At 7 weeks, ulcers were evoked by water immersion stress and gastric mucosa injury was measured previously described.

\section{Statistical analyses}

Data were expressed as means for all animals in treatment groups $(n=10)$. The Student's ttest, and the analysis of variance (ANOVA) test followed by Tukey Kramer's, Bonferroni's or Dunnett's multiple comparison tests were used to analyze data.

\section{Results}

Effect of different doses and dosing periods of cinnamon on the prevention of gastric ulcer

Figure 1a shows the dose-dependent preventative effect of cinnamon powder on gastric 
ulcers caused by water immersion stress. A $2 \mathrm{mg} / \mathrm{g}$ dose and $10 \mathrm{mg} / \mathrm{g}$ dose had no significant effects on preventing gastric ulcers compared with the control group, while the $100 \mathrm{mg} / \mathrm{g}$ dose was significantly effective for preventing gastric ulcers compared with the control group $(p<0.01)$.

The optimal dose period was investigated over one to four weeks. As shown in Figure $1 \mathrm{~b}$, the longer the period of administration, the better the gastroprotective benefit of a cinnamon powder diet. Gastric ulcers were significantly inhibited in mice that were placed on a cinnamon diet for four weeks compared with the control group $(p<0.01)$. Consequently, a cinnamon powder dose of $100 \mathrm{mg} / \mathrm{g}$ over a 4-week period was used for subsequent experiments.

\section{Effect of 4-week cinnamon powder diet on ulceration by water immersion stress in mice}

Humans are continually being exposed to different stressful conditions, and stress is known to aggravate gastric ulcer disease. Hence we investigated the effects of regular ingestion of cinnamon powder on stress-induced gastric ulcer. Permission to carry out this experiment was obtained from the committee regulating the ethical use of animals for scientific research in Kyoto University. The effect of a 4-week administration of cinnamon powder on water immersion stress-induced ulceration in mice is shown in figure 2. The mean ulcer index of mice in the cinnamon-treated group was significantly lower $(8 \mathrm{~mm})$ compared with the control group ( $14 \mathrm{~mm} ; p<0.01)$, indicating that regular ingestion of cinnamon powder may inhibit stress-induced ulcers. Physiological stress is thought to increase surface cell loss from fundic mucosa that is accompanied by a depression in epithelial proliferation 
[7].

\section{Effect of 4-week cinnamon powder diet on ulceration by oral administration of ethanol and $\mathrm{HCl}$ in mice}

It is well established that intragastric administration of noxious agents such as ethanol causes acute hemorrhagic erosion of the gastric mucosa in humans and other animals [11]. In the present study, mice ulcerated by oral administration of absolute ethanol or $0.6 \mathrm{M} \mathrm{HCl}$ had significantly lower ulcer index values $(4.2 \mathrm{~mm})$ than control groups if they were treated with cinnamon powder (17.3 mm; $p<0.01$; Figure 2 ). These values compare with the mean ulcer index value in the $\mathrm{HCl}$-induced ulcer group of mice fed a cinnamon diet of $1.8 \mathrm{~mm}$ versus the control $7.4 \mathrm{~mm}(p<0.01)$. $\mathrm{HCl}$ and ethanol are known to cause gastric ulcers by imparting direct physical damage to the gastric mucosa and eroding the mucosal layer [11]. The ethanol-induced ulcer model afforded a more visual and distinct ulcerogenesis than control groups, and a greater percentage protection against gastric ulcers following the cinnamon diet than the HCl-induced ulcer model.

\section{Effect of 4-week cinnamon powder diet on ulceration by NSAIDs in mice}

As shown in Figure 2, when ulcerogenesis was induced by oral administration of aspirin, a 4 week administration of cinnamon powder significantly protected mice against gastric ulcers $(p<0.05)$. Mice that were fed the cinnamon diet and underwent oral aspirin ulceration had a mean ulcer index value of $6.4 \mathrm{~mm}$ (26.45 \% protection) while the control group had a mean ulcer index value of $8.7 \mathrm{~mm}$. However, a 4-week administration of cinnamon powder did not protect mice against gastric ulcers induced by oral administration of indomethacin. The mean ulcer index value of mice that were fed the cinnamon diet and 
underwent oral indomethacin ulceration was $8.6 \mathrm{~mm}$ (18.87 \% protection) which was not statistically different from the control group with a mean ulcer index value of $10.6 \mathrm{~mm}$. No significant differences in ulcer index values were observed with ulceration induced by the subcutaneous administration of either indomethacin or aspirin in the cinnamon-treatment groups compared with the control groups (Figure 2).

\section{Effect of 4-week cinnamon diet on gastric mucosa thickness}

The effect of the 4-week cinnamon powder diet on the thickness of mice gastric mucosa was next investigated (Supplementary Figure 1). The cinnamon treated group of mice tended to have a thicker gastric mucosa compared with the control group. Statistical analysis was carried out using the student's t test to compare the mean thickness of the mucus layer of the cinnamon treated group with that of the control group. It was found that, the mean gastric mucosa thickness of the 4-week cinnamon-treated group (287.76 \pm 9.162 $\mu \mathrm{m})$ was significantly greater than that of the control group, which had an average thickness of $235.265 \pm 7.717 .54 \mu \mathrm{m}$.

\section{Effect of EACC and fractions on ulceration by ethanol in mice}

The 4-week administration of EACC (10 mg/g and $20 \mathrm{mg} / \mathrm{g}$ ) to mice caused a significant dose-dependent decrease in ulcer index values compared to control groups (Figure 3). Fractionation of EACC yielded $7.65 \mathrm{~g}$ of fraction 1 (a thick oily greenish yellow liquid), $0.58 \mathrm{~g}$ of fraction 2 (green amorphous powder), and $2.86 \mathrm{~g}$ of fraction 3 (a fibrous brownish semi-solid mass). The 4-week administration of fraction $1(84 \mathrm{mg} / \mathrm{g})$ and fraction 2 (6 $\mathrm{mg} / \mathrm{g}$ ) resulted in significant gastroprotective activity compared with the control group, suggesting that active gastroprotective constituents are contained in ethylacetate fractions 1 
and 2. The mean ulcer index values of mice in the different treatment groups were $8.6 \mathrm{~mm}$ for the EACC $10 \mathrm{mg} / \mathrm{g}$ group, $6.3 \mathrm{~mm}$ for the EACC $20 \mathrm{mg} / \mathrm{g}$ group, $10.5 \mathrm{~mm}$ for fraction 1, $11.7 \mathrm{~mm}$ for fraction 2, $17.3 \mathrm{~mm}$ for the sucralfate-treated group, and $8.5 \mathrm{~mm}$ for the control group. However, the percentage of gastroprotection afforded by whole cinnamon powder (75.7\%) was higher than that of either EACC $10 \mathrm{mg} / \mathrm{g}$ (50.3\%), EACC $20 \mathrm{mg} / \mathrm{g}$ (63.5\%), fraction 1 (39.3\%), or fraction 2 (32.4\%). The mean ulcer index of fraction 1,2 and 3 treated groups were all significantly greater than that of the cinnamon powder treated group (Figure 3).

\section{Chemical composition of EACC and fractions}

Phytochemical analysis of EACC by HPLC revealed that it consisted of CA, cinnamyl alcohol, cinnamyl acetate, coumarin and other unidentified compounds. GC/MS analysis of fraction 1 revealed that it contained mainly CA with some copaene. HPLC analysis of fraction 2 showed that it consisted mainly of CA and its alcohol, which was confirmed by H-NMR and C-NMR analyses after purification (Supplementary Figure 2). These results suggest that CA plays an important role in the gastroprotective benefits of a cinnamon diet.

\section{Effect of CA on ulceration by water immersion stress}

CA was administered to mice at doses of $0.98 \mathrm{mg}$ and $9.8 \mathrm{mg}$ per $\mathrm{g}$ of feed. CA was found to be significantly effective in preventing gastric ulcers at both doses of $0.98 \mathrm{mg}$ and 9.8 mg per g of feed compared to the control group at $p<0.05$ (Figure 4), which provided further evidence for the beneficial role of CA in the gastroprotective activity of a cinnamon powder diet. 


\section{Discussion}

The present study revealed that cinnamon powder exhibits potent gastroprotective activity in mice when consumed over a long period. The anti-ulcerogenic potential of a single dose oral administration of the aqueous extract of cinnamon powder has previously been reported $[5,6,12]$. However, the gastroprotective benefits of cinnamon powder administered in the form in which it is used in herbal medicine and as a spice is demonstrated here for the first time.

In the present study, ulcerogenesis was carried out using different models. A cinnamon diet clearly conferred effective protection against gastric ulcers induced by stress, ethanol or HCl. These models of ulceration induce gastric ulcer by a mechanism related to direct physical damage on the gastric mucosa thus suggesting a cytoprotective benefit of the cinnamon diet. The effects of the cinnamon diet on gastric ulcers caused by NSAIDs were also investigated. NSAIDs are thought to induce gastric damage by the nonspecific inhibition of cyclooxygenase (COX) and by markedly decreasing mucosal prostaglandin levels $[13,14,15,16,17,18]$. Cinnamon diet did not attenuate ulceration induced by subcutaneous injection of indomethacin or aspirin, but reduced the severity of gastric ulcers caused by oral administration of indomethacin although this effect was not significant. On the other hand, cinnamon diet significantly attenuated gastric ulcer caused by oral administration of aspirin. This effect was however weaker than that achieved against necrotizing agents. These results indicate that the efficacy of cinnamon diet against NSAIDs-induced gastric ulcers seems to be limited. It is thought that oral administration of aspirin might function as a mucosal barrier breaker rather than just as a COX inhibitor. This 
might partly explain why the gastroprotection against ulceration by oral administration of aspirin was somewhat effective. Results of histological examination revealed that the 4week cinnamon diet appeared to increase the thickness of the gastric mucosa. However, it is unclear whether the thickening of the gastric mucosa is as a result of increase in mucus secretion or whether this effect is directly associated with the gastroprotective benefit of cinnamon diet. We speculate that prostaglandin mediation might be involved in the gastroprotective activity of cinnamon diet but likely plays only a minor role. Other mechanisms different from prostaglandin synthesis might also be pertinent to the gastroprotective activity of cinnamon diet. These might include inhibition of gastric acid secretion, enhancement of gastric mucus secretion, mucosal blood flow increase, antioxidant activity, afferent sensory nerve stimulation or HSP gene expression [19, 20, 21, 22, 23, 24, 25, 26]. Further studies are required to clarify this.

We identified cinnamaldehyde as an active component of the gastroprotective benefits of a cinnamon diet. This finding is consistent with that of Harada et al. (1975) [27] who reported that cinnamaldehyde inhibited ulcerogenesis induced by water immersion stress. Shaik and colleagues also found that cinnamaldehyde had antiulcerogenic potential [28]. However, our present work showed that cinnamon powder exhibited greater gastroprotection than either EACC or the active fractions, leading us to surmise that cinnamaldehyde may not be the sole active compound responsible for the gastroprotection conferred by a cinnamon diet. Tanaka et al. (1987) [6] reported that 3-(2-hydroxyphenyl)propanoic acid and its O-glucoside isolated from the aqueous extract of cinnamon had an anti-ulcerogenic effect on serotonin-induced gastric ulcers in rats. However, they suggested 
that, unlike the active compounds, the aqueous extract showed multiple anti-ulcerogenic effects that were caused by more than two active components with different pharmacological effects. Eugenol, another compound present in cinnamon has also been shown to possess anti-ulcerogenic potential [29]. Taken together, these results suggest that a synergistic activity between active compounds is likely to account for the gastroprotective activity of cinnamon powder. Indeed, this is in agreement with the definition of 'active ingredients' as described in the guidelines of natural medicine issued by World Health Organization (Fact Sheet number 134).

We conclude that regular ingestion of cinnamon powder may offer gastroprotective benefits via cytoprotection, which validates its use in Kampo medicine prescriptions for stomach problems. Our work and that of others suggests that cinnamon powder may be useful as an alternative therapy in the management of recurrent or non- $H$. pylori gastric ulcers. However, the efficacy against NSAIDs- induced gastric ulcers appears to be limited.

\section{Acknowledgements}

This work was funded by Takeda Science Foundation (2009 grant), Kyoto, Japan. 


\section{References}

1. Anoop A, Jegadeesan M (2003) Biochemical studies on the anti-ulcerogenic potential of Hemidesmusindicus R.Br. varindicus. Journal of Ethnopharmacology 84:149-156.

2. Singh N, Shukla N, Singh P, Rajendran SM, Maurya R, Palit G (2010) Verbascoside isolated from Tectoniagrandis mediates protection in rats via inhibiting proton pump activity. Fitoterapia 81:755-761.

3. Ibrahim Abdulkarim Al Mofleh (2010) Spices, herbal xenobiotics and the stomach: Friends or foes? World journal of gastroenterology 16(22): 2710-2719.

4. Lin CC, Wu SJ, Chang CH, Ng LT (2003) Antioxidant activity of Cinnamomum cassia. Phytotherapy 17:726-730.

5. Akira T, Tanaka S, Tabata M (1986) Pharmacological studies on the antiulcerogenic activity of Chinese cinnamon. Planta Med. 52:440-443.

6. Tanaka S, Yoon YH, Fukumi H, Tabata M, Akira T, Okano K, Iwai M, Iga Y, Yokoyama K (1987) Antiulcerogenic compounds isolated from Chinese cinnamon. Planta Med. $55: 245-248$.

7. Kuwayama H, Eastwood GL (1985) Effects of water immersion restraint stress and chronic indomethacin ingestion on gastric antral and fundic epithelial proliferation. Gastroenterology 88:362-365.

8. Robert A, Nezamis EJ, Lancaster C, Hanchar AJ (1979) Cytoprotection by prostaglandins in rats: Prevention of gastric necrosis produced by alcohol, $\mathrm{HCl}, \mathrm{NaOH}$, hypertonic NaCl, and thermal injury. Gastroenterology 77:433-443.

9. Suzuki K, Araki H, Mizoguchi H, Furukawa O, Takeuchi K (2001) Prostaglandin E 
inhibits indomethacin-induced gastric lesions through EP-1 receptors. Digestion, 63:92101

10. Wang Z, Hasegawa J, Wang X, Matsuda A, Tokuda T, Miura N, Watanabe T (2011) Protective effects of ginger against aspirin-induced gastric ulcers in rats. Yonago Acta medica 54:11-19.

11. Iaquinto G, Giardullo N, Taccone W, Leandro G, Pasquale L, Luca L, Szabo S (2003) Role of endogenous endothelin-1 in ethanol induced gastric mucosal damage in humans. Dig. Dis. Sci. 48:663-669

12. Amar AR, Maysa ME (2010) Anti-ulcer effects of cinnamon and chamomile Aqueous Extracts in Rat Models. Journal of American Science 6 (12):209-216.

13. Okada M, Niida H, Takeuchi K, Okab S (1989) Role of prostaglandin deficiency in pathogenetic mechanism of gastric lesions induced by indomethacin. Dig. Dis. Sci. 34(5):694-702.

14. Peskar BM, Maricic N (1998) Role of prostaglandins in gastroprotection. Dig. Dis. Sci. 43: 23S-29S.

15. Wallace JL, McKnight W, Reuter BK, Vergnolle N (2000) NSAID-induced gastric damage in rats: requirement for inhibition of both cyclooxygenase 1 and 2 . Gastroenterology 119:706-714.

16. Whittle BJ (2003) Gastroprotective effects of nonsteroidal anti-inflammatory drugs. Fundam Clin Pharmacol 17(3):301-13.

17. Wallace JL (2008) Prostaglandins, NSAIDs, and gastric mucosal protection: Why doesn't the stomach digest itself? Physiol Rev 88: 1547-1565.

18. Robert A, Bottcher W, Galanska E, Kauffman GL Jr (1985) Lack of correlation 
between mucus gel thickness and gastric cytoprotection in rats. Gastroenterology 86: $610-674$.

19. Hollander D, Tarnawski A, Krause, WJ, Gergely H (1985) Protective effect of sucralfate against alcohol-induced gastric mucosal injury in the rat. Gastroenterology 88: 388-374.

20. Hudson N, Murray FE, Cole AT (1997) Effect of sucralfate on aspirin induced mucosal injury and impaired haemostasis in humans. Gut 41: 19-23.

21. Onodera S, Tanaka M, Aoyama M, Arai Y, Inaba N, Suzuki T, Nishizawa A, Shibata M, Sekine Y (1999) Antiulcer effect of Lafutidine on indomethacin-induced gastric antral ulcers in refed rats. Jpn. J. Pharmacol 80: 229-235.

22. Holzer P (1998) Neural emergency system in the stomach. Gastroenterology 1998(114):823-839.

23. Peskar BM (2001) Neural aspects of prostaglandin involvement in gastric mucosal defense. Journal of Physiology and pharmacology 52 (4): 555-568.

24. Ai HB, Zhang ZD (1990) Studies on the mechanism of gastric mucosal injury induced by water-immersion stress in rats. Sheng Li Xue Bao 42(5) 496-502.

25. Shrikant VJ, Kalyani AK, Urvashi VM, Sandesh RL, Payal DS, Heta GV, Rushi BV, Bhavin AV, Gajanan GK (2001) Alteration of gastric mucus secretion in rats treated with Abelmoschus esculentus seed mucilage. Der Pharmacia Lettre 2011: 3 (5) 183188.

26. Rujjanawate C, Kanjanapothi D, D. Amornlerdpison D, Pojanagaroon S (2005) Anti- 
gastric effect of Kaempfera parviflora. Journal of Ethnopharmacology 102 (2005) 120122.

27. Harada M, Yano S (1975) Pharmacological studies on Chinese cinnamon. Effects of cinnamaldehyde on the cardiovascular and digestive systems. Chem. Pharm. Bull. 23: 941-947.

28. Shaik MA, Aleem AK, Irshad A, MusaddiqM, Khaja SA, Polasa H, Venkateswar RL, Chittoor MH,Leonardo AS, Niyaz A (2005) Antimicrobial activities of Eugenol and Cinnamaldehyde against the human gastric pathogen Helicobacter pylori. Annals of Clinical Microbiology and Antimicrobials, 4:20.

29. Capasso, PL, Vuotto ML, Di Carlo G (2000) Preventive effect of eugenol on PAF and ethanol-induced gastric mucosal damage. Fitoterapia 71: 131-137

\section{Figures and Legends}
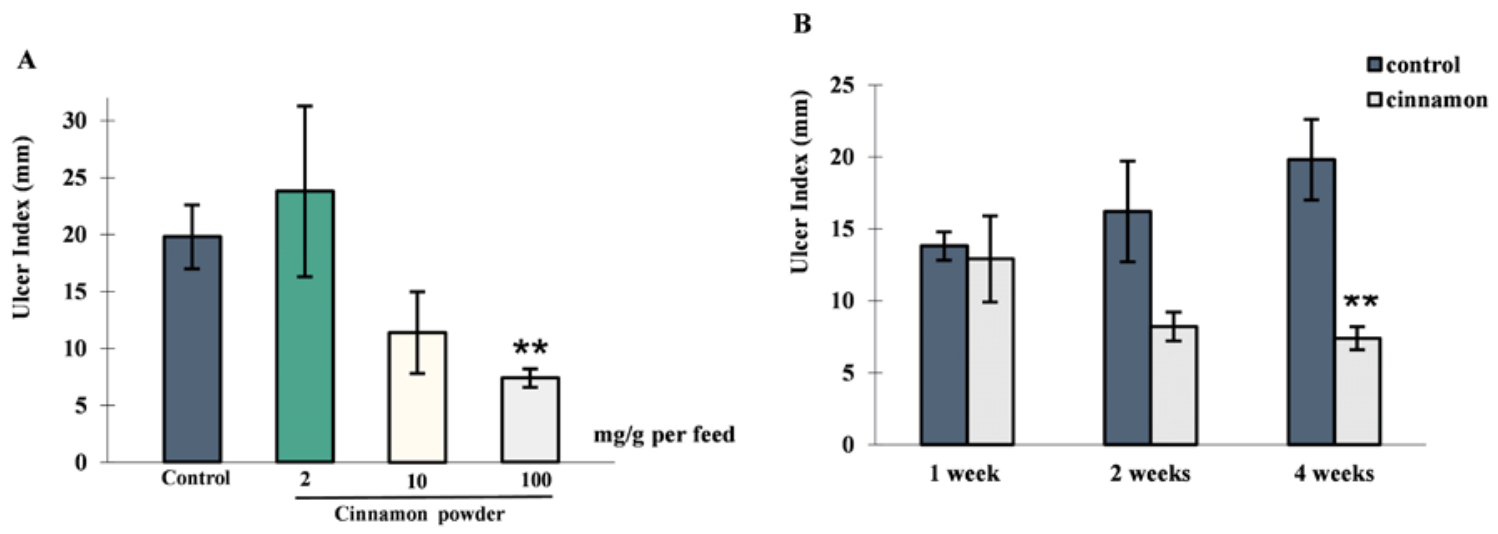

Figure 1. Optimization of cinnamon powder diet dose and dosing period for preventing gastric ulcers induced by water immersion stress. A, Graph showing dose dependency of 
cinnamon powder after 4-week administration. Data are presented as mean \pm SEM values of 10 mice. Statistical differences between cinnamon (light bars) vs. the control group (dark bars) were calculated by ANOVA, followed by Tukey-Kramer's multiple comparison test. B, Graph showing effective dose period of cinnamon powder diet (100 mg/g per feed) over 1-, 2- and 4-week periods. Statistical differences vs. the control group were calculated by the Student's t-test. * $P<0.05 *$ ** $P<0.01$ vs Control.

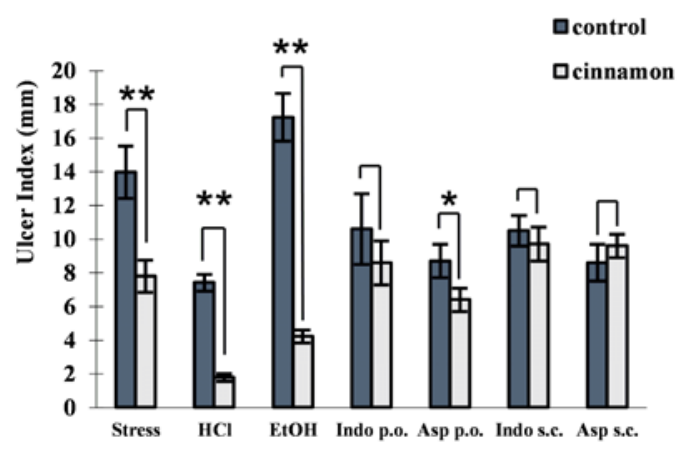

Figure 2. Graph showing effect of a 4-week cinnamon powder diet on gastric ulcers caused by water immersion stress (Stress), administration of $\mathrm{HCl}$ or ethanol (EtOH), oral administration of indomethacin (Indo p.o.) or aspirin (Asp p.o.), or subcutaneous administration of indomethacin (Indo s.c.) or aspirin (Asp s.c.). Data are presented as mean \pm SEM values of 10 mice. Statistical differences between cinnamon (light bars) vs. the control group (dark bars) were calculated by the Student's t-test. ${ }^{*} P<0.05{ }^{*}{ }^{*} P<0.01$ vs Control. 


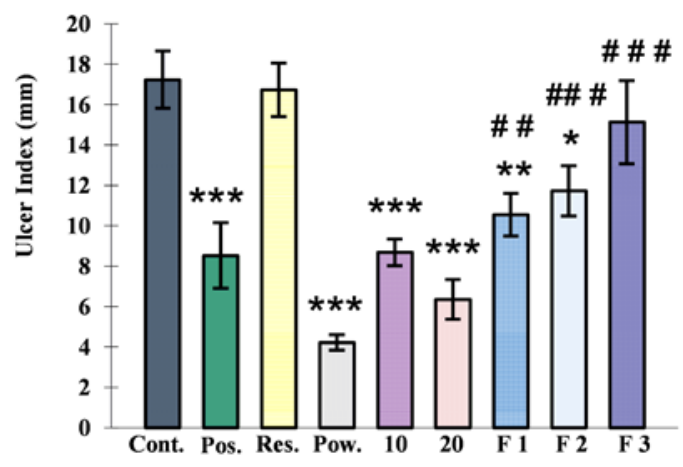

Figure 3. Graph showing the effects of EACC and fractions on ethanol-induced ulceration in mice. Represented treatment groups were control (Cont.), positive control (Pos.), cinnamon residue (Res.), cinnamon powder (Pow.), $10 \mathrm{mg} / \mathrm{g}$ cinnamon extract (10), 20 mg/g cinnamon extract (20), fraction 1 (F1), fraction 2 (F2), and Fraction 3 (F3). Data are presented as mean \pm SEM values of 10 mice. Statistical differences vs. the control group were calculated by ANOVA, followed by Bonferroni's multiple comparison test. *** $P<$ 0.001, ** $P<0.01, \quad * P>0.05$ vs Control. \#\#\# $P<0.001$, \#\# $P<0.01$ vs Cinnamon powder.

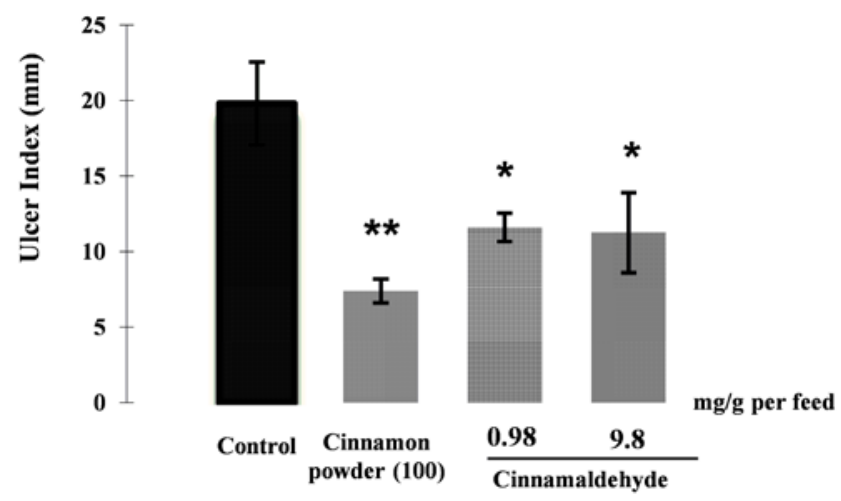


Figure 4. Graph showing effect of cinnamaldehyde on ulceration induced by water immersion stress in mice. Represented treatment groups were control, cinnamon powder, $0.98 \mathrm{mg} / \mathrm{g}$ and $9.8 \mathrm{mg} / \mathrm{g}$ cinnamldehyde. Data are presented as mean \pm SEM values of 10 mice. Statistical differences vs. the control group were calculated by ANOVA, followed by Dunnett's and Tukey-Kramer's multiple comparison tests. ${ }^{* *} P<0.01, \quad{ }^{*} P<0.05$ vs Control.

\section{Supplementary figure legends}

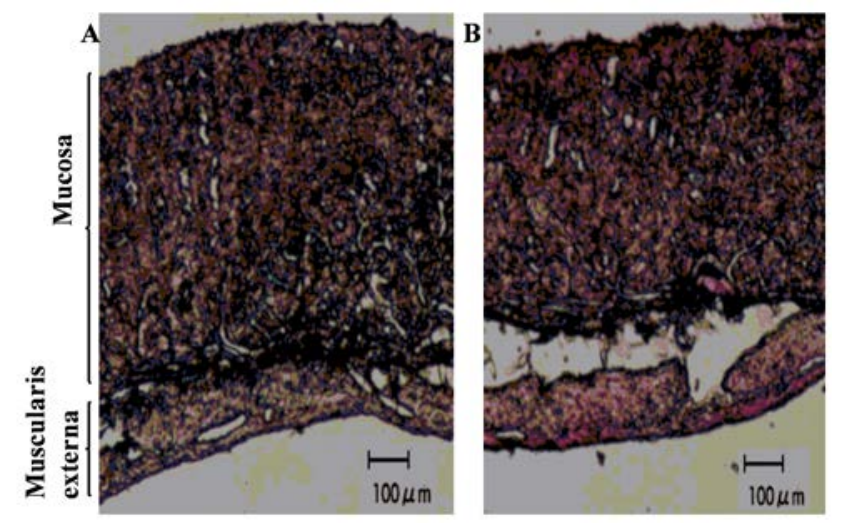

Supplementary Figure 1. Pictomicrograph showing thickened mouse gastric mucosa after completion of the 4-week cinnamon powder diet. A, Cinnamon-treated group. B, Control 
group. Scale bar, $100 \mu \mathrm{m}$.

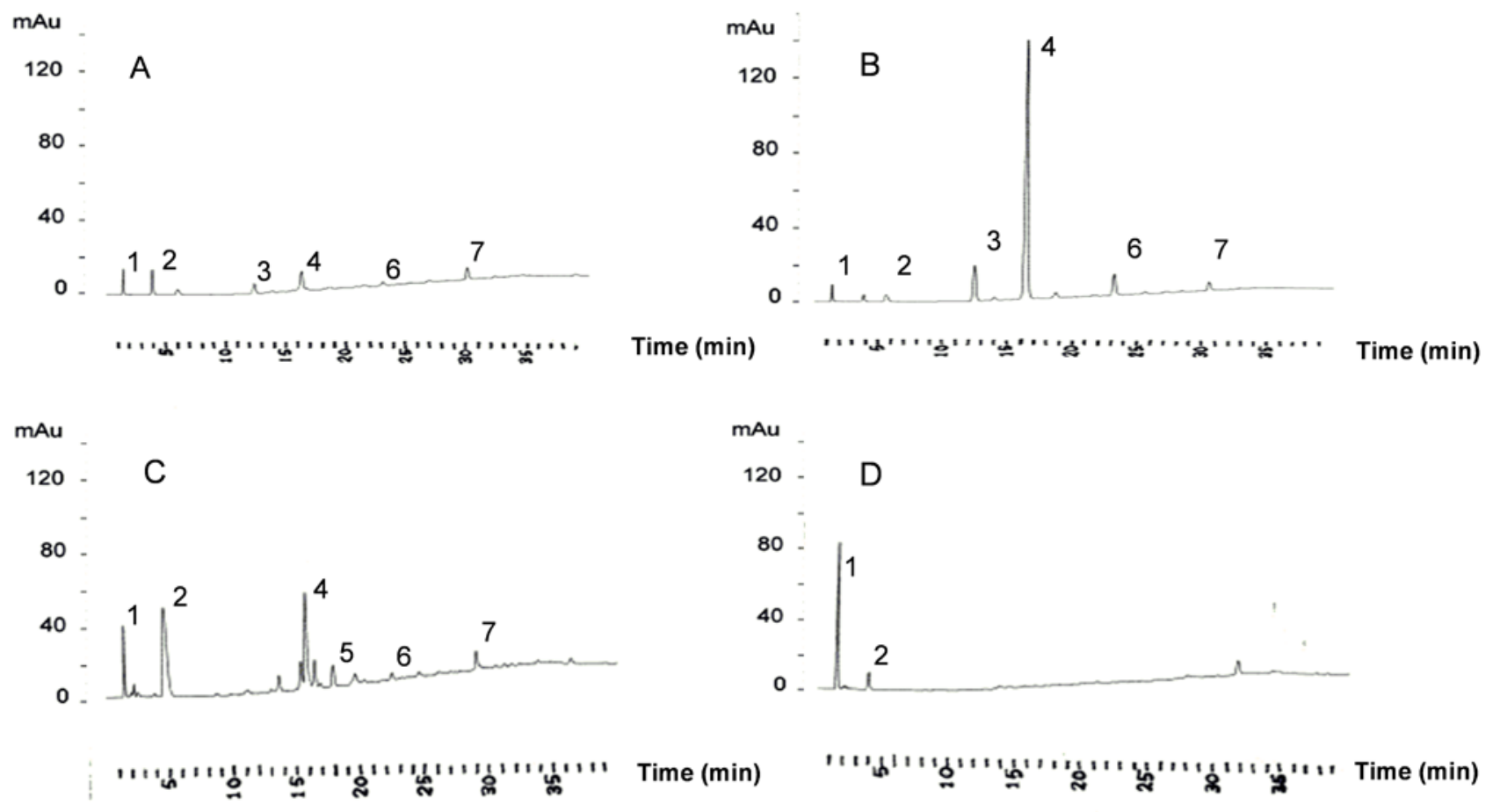

Supplementary Figure 2. Chemical fingerprints of EACC (A), fraction 1 (B), fraction 2 (C) and fraction 3 (D). Peaks 1, unidentified; 2, cinnamylalcohol; 3, coumarin; 4, cinnamaldehyde; 5, eugenol; 6, cinnamyl acetate; 7, unidentified. HPLC conditions: Column pack: ODS/R: $10 \mu \mathrm{l}, 120$ A, 4.6 × 250 mm. I.D. Program: 37 \% MeOH (at 0 min) - $100 \% \mathrm{MeOH}$ (at $30 \mathrm{~min}$ ). Flow Rate: $1 \mathrm{ml} / \mathrm{min}$. Injection volume: $3 \mu \mathrm{l}$. Detection: UV $254 \mathrm{~nm}$. 